Check for updates

Cite this: Mater. Adv., 2021, 2, 6068

Received 13th July 2021 Accepted 10th August 2021

DOI: $10.1039 / \mathrm{d} 1 \mathrm{ma00602a}$

rsc.li/materials-advances

\title{
Purely organic and saturated red emitters for a non-doped electroluminescent device with an EQE of $6.3 \%$ and low efficiency roll-off $\dagger$
}

\author{
Lei Chen, (D) $\ddagger^{*^{a}}$ Xuehan $\mathrm{He} \ddagger^{\mathrm{b}}$ and Yongbiao Zhao*c
}

\begin{abstract}
Red organic light emitting diodes (OLEDs) based on purely organic emitters with high efficiency, good colour chromaticity coordinates and low efficiency roll-off features are in high demand for display and lighting applications. Additionally, to simplify the device fabrication processes, it is desirable to develop OLEDs with non-doped emission layers. In this work, three 2,1,3-naphthodiazole-based red emissive model compounds (RMCs) with tailored electron-donating structures were synthesized. In comparison with the orange emissive RMC1 and the near infrared emissive RMC3, RMC2 with a moderate electron donating ability demonstrates a pure red peak emission at $625 \mathrm{~nm}$. Moreover, RMC2 shows high fluorescence quantum efficiency $\left(\Phi_{f}\right)$ in both diluted solution (0.76) and neat films $(0.41)$. Non-doped saturated red OLEDs based on RMC2 with a maximum luminous efficiency of $5.3 \mathrm{~cd} \mathrm{~A}^{-1}$, a maximum external quantum efficiency (EQE) of $6.3 \%$ and good $\mathrm{CIE}$ coordinates of $(0.64,0.35)$ are demonstrated. In addition, the device shows a slight efficiency roll-off feature, displaying an EQE of $5.1 \%$ at a brightness of $1000 \mathrm{~cd} \mathrm{~m}^{-2}$.
\end{abstract}

\section{Introduction}

Organic light-emitting diodes (OLEDs) have quickly spread into our daily lives as a new generation display and lighting technology. Purely organic emitters (POEs) with internal quantum efficiency (IQE) close to $100 \%$ have attracted significant attention to substitute high-cost, noble-metal based phosphorescent emitters. Blue ${ }^{1-4}$ and green ${ }^{5,6}$ OLEDs employing thermally activated delayed fluorescence (TADF) POEs have been reported with external quantum efficiency (EQE) values around 30\%. Many red OLEDs using TADF ${ }^{7-38}$ or radical-based ${ }^{39}$ POEs have also been obtained with EQE values beyond $10 \%$. Some of the reported red POEs showed emission peaks beyond $630 \mathrm{~nm},{ }^{15-39}$ which is required to realize good colour chromaticity coordinates (CIE: $x \geq 0.62, y \leq 0.37$ ) for display applications. Among them, most devices show significant efficiency roll-off at high current densities, and only a few literature studies report EQE

\footnotetext{
${ }^{a}$ School of Biomedical Engineering, Sun Yat-Sen University, Guangzhou,

Guangdong, 510006, China. E-mail: chenlei59@mail.sysu.edu.cn

${ }^{b}$ Teaching and Experiment Centre, Sun Yat-Sen University, Guangzhou, Guangdong, 510006, China

${ }^{c}$ School of Physics \& Astronomy, Yunnan University, Kunming, Yunnan, 650091, China. E-mail: yzhao@ynu.edu.cn

$\dagger$ Electronic supplementary information (ESI) available: Experimental materials and methods, characterization of all compounds, and supplementary figures. See DOI: $10.1039 / \mathrm{d} 1 \mathrm{ma} 00602 \mathrm{a}$

\# L. Chen and X. He contributed equally to this article.
}

values of over $5 \%$ at a brightness of $1000 \mathrm{~cd} \mathrm{~m}^{-2} \cdot 22,23,30,34,37$ Besides the popular TADF-based POEs, "hot exciton"-based POEs, ${ }^{40}$ which can convert triplet excitons into singlet excitons from the high-lying excited state $\left(\mathrm{T}_{2}\right)$, have been reported with a maximum EQE of $10.5 \%, 20.2 \%$ and $6.8 \%$ for blue, ${ }^{41,42}$ green $^{43}$ and red $^{44}$ OLEDs, respectively.

A dopant-host system is usually adopted to realize efficient electroluminescence (EL) and improved device lifetime. ${ }^{45}$ Precise control of the doping concentration is required to suppress the serious efficiency roll-off caused by exciton annihilation at high doping concentrations and high current densities. In order to simplify the device structures and fabrication processes, it is desirable to construct highly efficient red OLEDs with non-doped emission layers (EML). ${ }^{18}$ TADF-based nondoped red OLEDs with EQE values around 10\% have been reported ${ }^{25,34}$ however, they suffer from either poor red colour saturation or significant efficiency roll-off, ${ }^{25}$ or high turn on voltage $^{34}$ issue. And for "hot exciton" based non-doped red OLEDs there is still much room to improve their EQE above the $5 \%$ criteria. $^{27,46}$

In this work, through tuning the electron-donating ability of previously reported 2,1,3-naphthodiazole (NT) derivatives with the "hot exciton" feature in the EL process, ${ }^{47-50}$ three red emitters (RMC1, RMC2, and RMC3) were synthesized as shown in Fig. 1. Among them, RMC2 with a moderate electron donating ability has high fluorescence quantum efficiency $\left(\Phi_{\mathrm{f}}\right)$ in both diluted solution and solid films. Its neat film exhibits a 


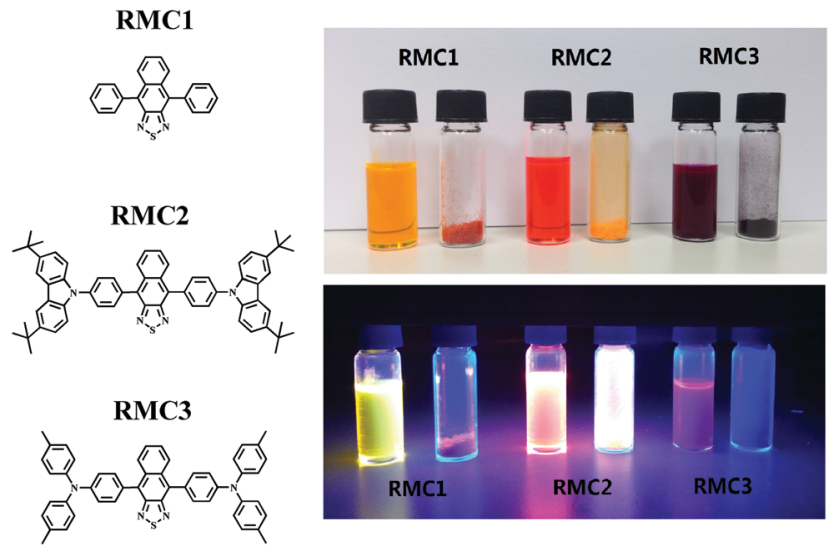

Fig. 1 Molecular structures of RMC $1-3$ (left); their photographs in $10^{-5} \mathrm{M}$ toluene solution and in powder form under room light and $365 \mathrm{~nm}$ UV light irradiation (right).

pure red emission peak at around $625 \mathrm{~nm}$. It realized a trade-off between $\Phi_{\mathrm{f}}$ and colour purity as well as a trade-off between carrier injection and recombination. As a result, non-doped red OLEDs based on RMC2 with a device configuration of ITO/ $\mathrm{MoO}_{3} / \mathrm{TCTA} / \mathrm{EML} / \mathrm{TPBI} / \mathrm{LiF} / \mathrm{Al}$ realized a luminous efficiency (LE) of $3.6 \mathrm{~cd} \mathrm{~A}^{-1}$, an EQE value of $3.8 \%$ and CIE coordinates of $(0.63,0.36)$. Moreover, by the introduction of a super thin
TPBI layer $(1 \mathrm{~nm})$ between the hole transporting layer (HTL) and the EML to further balance the hole/electron current and confine the carrier recombination zone completely in the EML, the optimized device achieved a maximum LE of $5.3 \mathrm{~cd} \mathrm{~A}^{-1}$, an EQE of $6.3 \%$ and CIE coordinates of $(0.64,0.35)$. In addition, the device demonstrates a small efficiency roll-off feature, with an EQE value of $6.3 \%$ and $5.1 \%$ respectively at a brightness of $100 \mathrm{~cd} \mathrm{~m}^{-2}$ and $1000 \mathrm{~cd} \mathrm{~m}^{-2}$.

\section{Results and discussion}

According to our previous studies, ${ }^{51,52}$ we selected the NT unit as an electron acceptor because it possesses stronger electron withdrawing ability due to one more benzene ring fused in its molecular structure compared to the benzothiadiazole (BT) unit. The emission wavelength of its derivatives can be effectively red-shifted. ${ }^{53-55}$ More importantly, the fused ring structure leads to enhanced molecular rigidity, which is beneficial for achieving high $\Phi_{\mathrm{f}}$ in the solution state. Benzene, 3,6-di-tert-butyl-9H-carbazolylbenzene $(t$-BuCzB) and $N, N$-di-(4-methylphenyl)aminobenzene (DMPAB) were chosen as the donor units with sequentially increased electron-donating ability. Benzene is a weak donor. DMPAB is a strong donor due to the lone pair electrons of nitrogen atoms. In comparison with DMPAB, the $t$-BuCzB unit is a moderate electron donor because the dihedral angle between the carbazole moiety
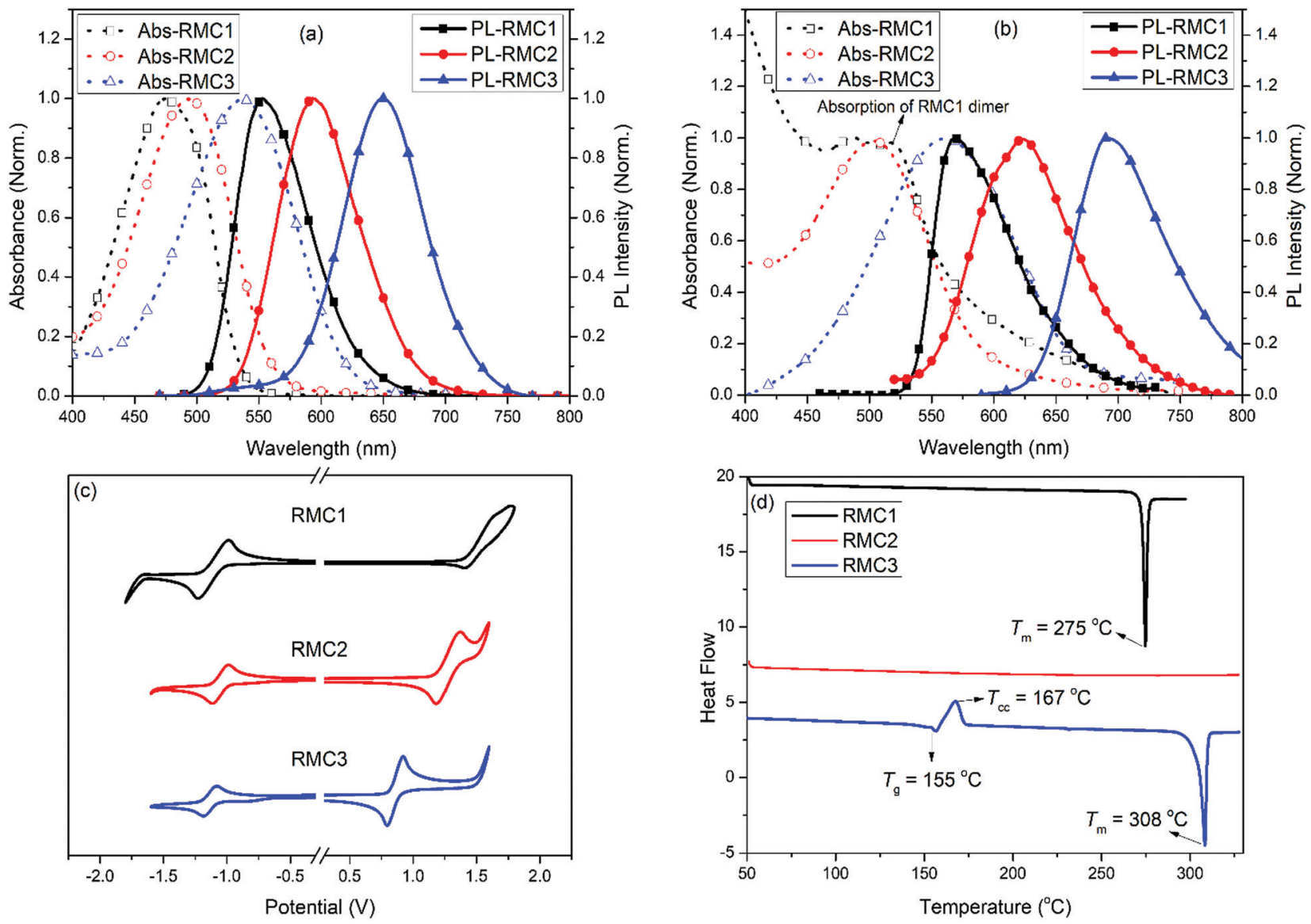

Fig. 2 The absorption and PL spectra in toluene solution (a) and film states (b) as well as CV (c) and DSC (d) curves of the RMCs. 
and phenyl bridge is relatively larger than that of diphenylamine and the phenyl bridge. Part of the charge of the nitrogen lone pair will be delocalized in the carbazole moiety, so its electron donating strength is less than that of triphenylamine derivatives. ${ }^{56}$ Bulky tert-butyl groups were introduced at the C-3 and C- 6 positions of the carbazole moiety to further suppress the aggregation in the solid state. The detailed synthetic routes and characterization data of the three RMCs are described in the ESI. $\dagger$

The photophysical, electrochemical, and thermal properties of the RMCs are shown in Fig. 2 and the corresponding data are listed in Table 1. In diluted toluene solution, the absorption/ emission peaks of RMC1, RMC2 and RMC3 are 476/553 nm, 493/593 $\mathrm{nm}$ and 537/649 $\mathrm{nm}$, respectively. Their absorption, emissive peaks and Stokes shifts gradually increased. These are consistent with their intramolecular charge transfer ability. In the neat film state, their absorption/emission peaks are bathochromically shifted to $487 / 569 \mathrm{~nm}, 503 / 622 \mathrm{~nm}$ and $561 / 691 \mathrm{~nm}$. The redshift should be due to the aggregation effect of the compounds. Interestingly, RMC1 also displays another strong absorption peak at $515 \mathrm{~nm}$. The first peak at $487 \mathrm{~nm}$ can be ascribed to the absorption of the RMC1 monomer. The latter at $515 \mathrm{~nm}$ should be due to the absorption of the RMC1 $J$-dimer, due to its good molecular planarity. To verify the speculation, we acquired the absorbance of RMC1 in doped polystyrene (PS) films (10 wt\%) as shown Fig. S1a (ESI $\dagger$ ). There is only one absorption peak around $466 \mathrm{~nm}$. No other longer wavelength absorption was detected. Compared with doped films, the neat films of the three RMCs show bathochromic shifted absorption. Among them, the absorption of RMC2 only red-shifts about $11 \mathrm{~nm}$, which is much smaller than that of RMC1 (21/47 $\mathrm{nm}$ ) and RMC3 (23 nm), implying that the aggregation effect of RMC2 is effectively suppressed. As a result, the $\Phi_{\mathrm{f}}$ of the RMC2 in neat films remains as high as $41 \%$, while, the $\Phi_{\mathrm{f}}$ of RMC1 and RMC3 neat films is decreased to $15 \%$ and $9 \%$, respectively.

Cyclic voltammetry (CV) measurements were conducted to investigate the electrochemical properties of the RMCs (Fig. 1c). Their onset oxidation voltages and onset reduction voltages as well as the highest occupied molecular orbital (HOMO) and lowest unoccupied molecular orbital (LUMO) energy levels are listed in Table 1. These RMCs possess almost the same LUMOs of around $-3.40 \mathrm{eV}$ because they have the same electron withdrawing unit. However, due to the improved electron donating ability of RMC1, RMC2 and RMC3, their HOMO energy levels gradually increase from $-5.82 \mathrm{eV}$ to $-5.58 \mathrm{eV}$ and $-5.21 \mathrm{eV}$. The results agree with their photophysical properties very well.
The thermal properties of the RMCs were acquired by differential scanning calorimetry (DSC) and thermogravimetric analysis (TGA). It can be seen from Fig. 2d that RMC1 has a sharp and intense crystalline transition at around $275{ }^{\circ} \mathrm{C}$ without glass transition. RMC3 undergoes a glass transition at around $155{ }^{\circ} \mathrm{C}$ as well as a cold crystallization process and a crystalline transition at around $167{ }^{\circ} \mathrm{C}$ and $308{ }^{\circ} \mathrm{C}$, respectively. RMC2 does not undergo the cold crystallization process and crystalline transition during the measurement temperature range, indicating that it is in an amorphous state. The DSC results are consistent with the solid state appearance of the RMCs: a needle-like red crystal for RMC1, a fluffy orange-red solid for RMC2 and a semi-crystalline purple solid for RMC3. This phenomenon confirms the restricted self-aggregation of RMC2 in the solid state. This can be ascribed to the more twisted molecular conformation and the existence of bulky tert-butyl groups. The high thermal decomposition temperature $\left(394{ }^{\circ} \mathrm{C}\right.$, Fig. S2, ESI $\dagger$ ) of RMC2 further guarantees its thermal stability in EL devices. All these indicate that RMC2 is a good candidate for non-doped red electroluminescent devices. RMC1 and RMC3 are not suitable for non-doped red devices due to their orange-red or near-infrared emissive color and low PL efficiency in neat films.

In order to investigate the EL properties of RMC2, we first fabricated type A device with a simple structure of ITO/RMC2/ $\mathrm{TPBI} / \mathrm{LiF}(1 \mathrm{~nm}) / \mathrm{Al}(100 \mathrm{~nm})$. Here, TPBI stands for 1,3,5-tris $(N$-phenylbenzimiazole-2-yl)benzene, which is employed as the electron transporting layer (ETL) and the hole blocking layer (HBL). The energy level alignments of the device are illuminated in Fig. 3. The thickness of the non-doped EML and TPBI layer is optimized to be $40 \mathrm{~nm}$ and $20 \mathrm{~nm}$, respectively. The current density-LE curves, current density-EQE curves and EL spectra of the device are shown in Fig. 4. The device performance is listed in Table 2 . It realized a maximum LE of $1.5 \mathrm{~cd} \mathrm{~A}^{-1}$, a power efficiency (PE) of $1.6 \mathrm{~lm} \mathrm{~W}^{-1}$ and an EQE of $2.6 \%$ with an emission peak at $654 \mathrm{~nm}$ and CIE coordinates of $(0.67,0.33)$.

Since the HOMO energy level of RMC2 is about $-5.6 \mathrm{eV}$, which is much lower than the work function of UV-Ozone treated ITO $(-5.0 \mathrm{eV})$, the hole injection of the device should be inefficient due to the large energy barrier. The $\mathrm{MoO}_{3}$ buffer layer and the tris(4-carbazoyl-9-ylphenyl)amine (TCTA) HTL were introduced to fabricate a type $\mathrm{B}$ device with an improved hole-injection efficiency. $\mathrm{MoO}_{3}$ is an efficient hole injection layer for optoelectronic devices. ${ }^{57}$ Although with a wide bandgap of about $3.1 \mathrm{eV}$, the mid-gap states in the $\mathrm{MoO}_{3}$ film can be

Table 1 The photophysical, electrochemical and thermal properties of the RMCs

\begin{tabular}{|c|c|c|c|c|c|c|c|c|c|c|c|}
\hline & $\lambda_{\mathrm{abs}}{ }^{a}[\mathrm{~nm}]$ & $\lambda_{\mathrm{emi}}[\mathrm{nm}]$ & $\Phi_{\mathrm{f}}[\%]$ & $E_{\mathrm{red}}^{\text {onset } b}[\mathrm{~V}]$ & $E_{\text {LUMO }}[\mathrm{eV}]$ & $E_{\text {oxd }}^{\text {onset }}[\mathrm{V}]$ & $E_{\text {HOMо }}[\mathrm{eV}]$ & $E_{\mathrm{g}}[\mathrm{eV}]$ & $T_{\mathrm{g}}{ }^{c}\left[{ }^{\circ} \mathrm{C}\right]$ & $T_{\mathrm{m}}\left[{ }^{\circ} \mathrm{C}\right]$ & $T_{\mathrm{d}}^{d}\left[{ }^{\circ} \mathrm{C}\right]$ \\
\hline RMC1 & $476 / 487$ & $553 / 569$ & $91 / 15$ & -1.01 & -3.39 & 1.42 & -5.82 & 2.43 & n.a. & 275 & 447 \\
\hline $\mathrm{RMC} 2$ & $493 / 503$ & $593 / 622$ & $76 / 41$ & -0.99 & -3.41 & 1.18 & -5.58 & 2.17 & n.a. & n.a & 394 \\
\hline RMC3 & $537 / 561$ & $649 / 691$ & $35 / 9$ & -1.03 & -3.37 & 0.81 & -5.21 & 1.84 & 155 & 308 & 242 \\
\hline
\end{tabular}

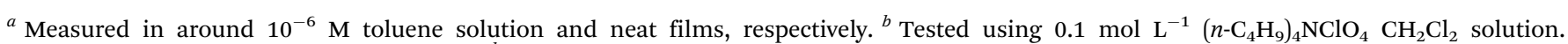

${ }^{c}$ Extracted from the second heating curves. ${ }^{d}$ Temperature at $5 \%$ weight loss. 


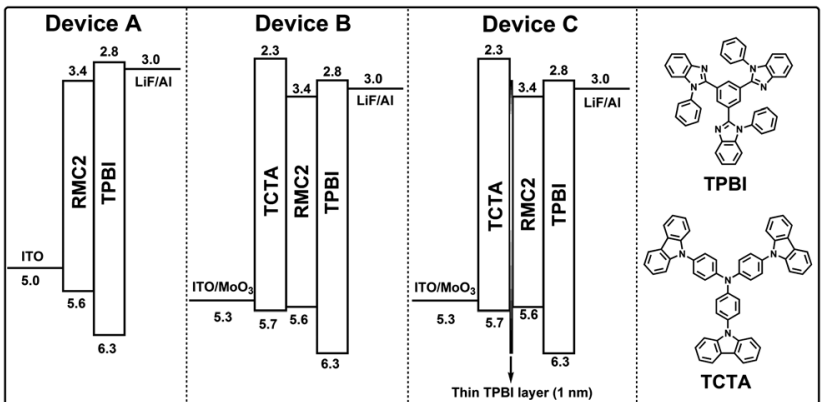

Fig. 3 The device configurations and energy level alignments of devices $A, B$ and $C$ as well as the chemical structures of TPBI and TCTA.

formed by partial filling of unoccupied $4 \mathrm{~d}$ orbitals of molybdenum atoms due to the existence of oxygen vacancies in thermally evaporated $\mathrm{MoO}_{3}$ thin films. The gap states align well with the HOMO level of the organic HTL layer and thus lower the hole injection barrier at the $\mathrm{HTL} / \mathrm{MoO}_{3}$ interface. ${ }^{58}$ TCTA exhibits almost the same HOMO level $(-5.7 \mathrm{eV})$ as that of RMC2, and the hole-injection energy barrier at the HTL/EML interface is negligible. As a result, the maximum brightness was greatly improved from $2512 \mathrm{~cd} \mathrm{~m}^{-2}$ of device A to $10270 \mathrm{~cd} \mathrm{~m}^{-2}$ of device B with a configuration of ITO/ $\mathrm{MoO}_{3}(10 \mathrm{~nm}) / \mathrm{TCTA}(40 \mathrm{~nm}) /$ $\mathrm{RMC}(20 \mathrm{~nm}) / \operatorname{TPBI}(40 \mathrm{~nm}) / \mathrm{LiF}(1 \mathrm{~nm}) / \mathrm{Al}(100 \mathrm{~nm})$. The optimized device achieved a maximum LE of $3.6 \mathrm{~cd} \mathrm{~A}^{-1}$, a PE of $3.1 \mathrm{~lm} \mathrm{~W}^{-1}$ and an EQE of $3.8 \%$ with an emission peak at $646 \mathrm{~nm}$ and CIE coordinates of $(0.63,0.36)$.

The good device performance could be attributed to not only the fine-tuned photophysical properties of RMC2 in the PL process but also the good charge recombination efficiency in the EL process. Non-doped red OLEDs based on aryl amine derivatives usually show predominantly hole carrier transporting features, ${ }^{59,60}$ leading to an unbalanced hole and electron carrier flow and unwanted exciton recombination zone located at the EML/ETL interface. Replacing aryl amine by carbazole may lead to more balanced hole and electron charge carriers. We fabricated single-carrier devices based on RMC2 and RMC3 to verify the speculation. The hole-only device structure is $\mathrm{ITO} / \mathrm{MoO}_{3}(5 \mathrm{~nm}) /$ $\operatorname{TCTA}(20 \mathrm{~nm}) / \operatorname{EML}(70 \mathrm{~nm}) / \operatorname{TCTA}(20 \mathrm{~nm}) / \mathrm{MoO}_{3}(5 \mathrm{~nm}) / \mathrm{Al}$. The electron-only device structure is ITO/TPBI $(20 \mathrm{~nm}) / \operatorname{EML}(70 \mathrm{~nm}) /$ $\operatorname{TPBI}(20 \mathrm{~nm}) / \mathrm{LiF}(1 \mathrm{~nm}) / \mathrm{Al}$. Their current density-voltage curves are shown in Fig. 4d; the inset figure shows the calculated ratio of hole/electron carriers. It can be seen that RMC3 with a triphenyl amine donor group shows a much larger hole/electron current ratio than that of RMC2 with a carbazole donor unit. This
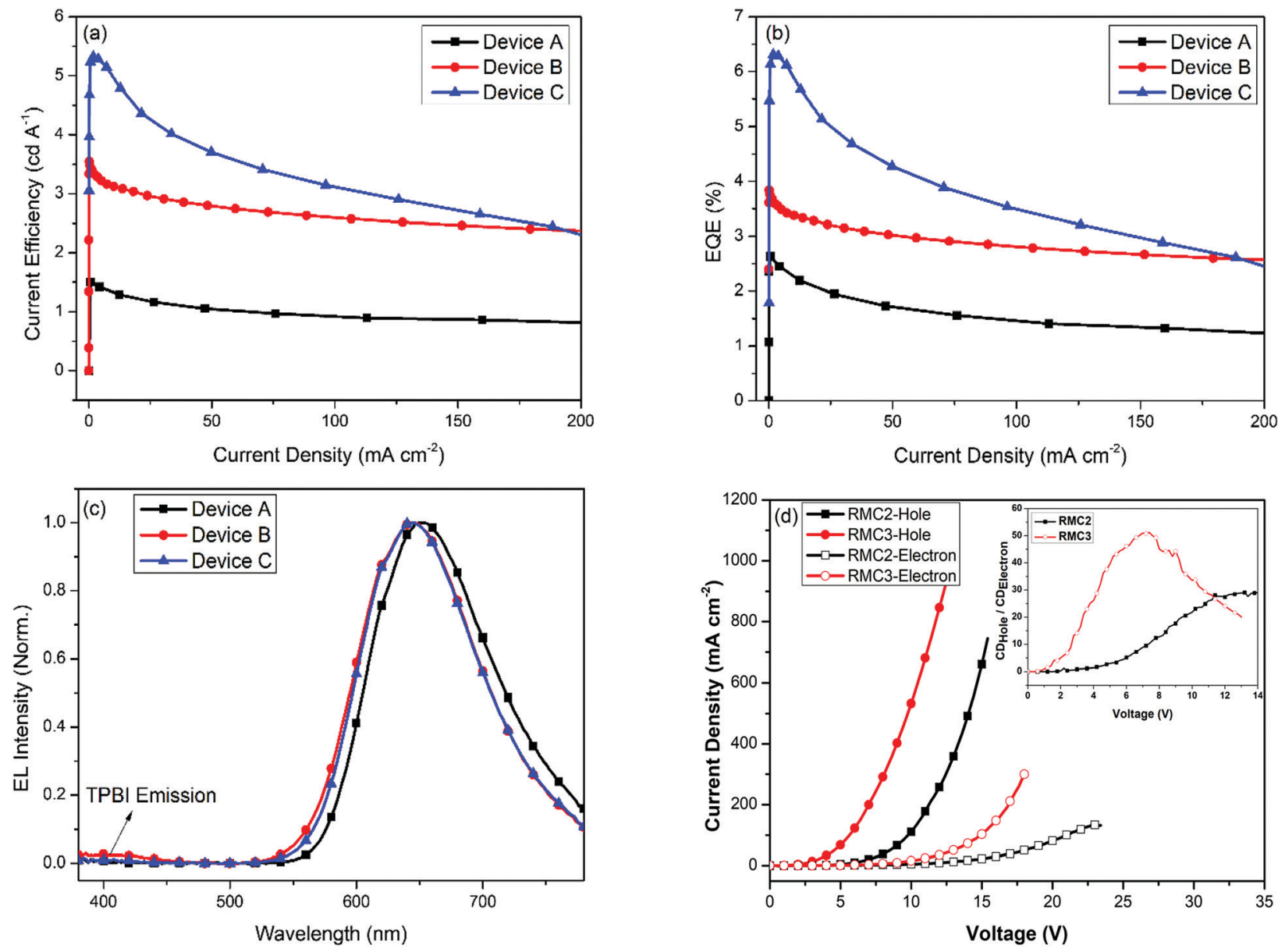

Fig. 4 The current density-luminous efficiency curves (a), current density-external quantum efficiency (b) curves and the EL spectra (c) of RMC2 based device structures A, B and C as well as the current density-voltage curves of single carrier devices based on RMC2 and RMC3 (d). 
Table 2 The electroluminescence performance of the non-doped red devices of A, B and C types

\begin{tabular}{|c|c|c|c|c|c|c|c|}
\hline Device & $V_{\mathrm{on}}{ }^{a}[\mathrm{~V}]$ & Brightness $^{b}\left[\mathrm{~cd} \mathrm{~m}^{-2}\right]$ & $\mathrm{LE}^{c}\left[\mathrm{~cd} \mathrm{~A}{ }^{-1}\right]$ & $\mathrm{PE}^{c}\left[\operatorname{lm} \mathrm{W}^{-1}\right]$ & $\operatorname{EQE}^{c}[\%]$ & $\lambda_{\max }{ }^{d}[\mathrm{~nm}]$ & $\begin{array}{l}\mathrm{CIE} \\
(x, y)^{d}\end{array}$ \\
\hline A & 3.0 & 2515 & $1.5 / 1.4 / 0.9$ & $1.6 / 1.2 / 0.5$ & $2.6 / 2.4 / 1.4$ & 654 & $(0.67,0.33)$ \\
\hline B & 3.2 & 10270 & $3.6 / 3.3 / 2.9$ & $3.1 / 2.3 / 1.5$ & $3.8 / 3.6 / 3.1$ & 646 & $(0.63,0.36)$ \\
\hline $\mathrm{C}$ & 3.5 & 4850 & $5.3 / 5.3 / 4.3$ & $3.3 / 3.0 / 1.8$ & $6.3 / 6.3 / 5.1$ & 646 & $(0.64,0.35)$ \\
\hline
\end{tabular}

${ }^{a}$ At $1.0 \mathrm{~cd} \mathrm{~m}^{-2} .{ }^{b}$ Maximum value. ${ }^{c}$ Maximum value, estimated value at 100 and $1000 \mathrm{~cd} \mathrm{~m}^{-2} .{ }^{d}$ At $7.0 \mathrm{~V}$.

demonstrates that the hole/electron current indeed becomes more balanced in the RMC2 based device. From the view of material design, although both the hole and electron currents of RMC2 are inferior to those of RMC3, the more balanced holeelectron carriers may lead to a higher recombination efficiency, achieving better trade-off between the charge injection and recombination efficiency in the EL process.

According to the single-carrier device, it can be seen that replacing triphenyl amine with carbazole units is indeed beneficial for the hole-electron carrier balance, but it is still inadequate. It can be verified by the EL spectra of device B (Fig. 4c), which displays a tail emission around $400 \mathrm{~nm}$ arising from the TPBI ETL. ${ }^{61}$ This indicates that part of the exciton was generated in the TPBI layer, due to the improved hole injection ability. Other hole blocking/electron transporting materials, such as 2,9-dimethyl-4,7-diphenyl-1,10-phenanthroline (BCP), have a smaller HOMO level, may have more efficient hole blocking ability, and their electron mobility is lower than that of TPBI. ${ }^{62}$ Employing it as the HBL layer of non-doped red OLED leads to even inferior device performance. ${ }^{63}$ To resolve this problem, we fabricated device $\mathrm{C}$ by utilizing a super thin TPBI layer inserted between the TCTA layer and EML (see in Fig. 3) of device $\mathrm{C}$ to fine control the hole injection without affecting the electron transportation. The thickness of the thin TPBI layer was optimized to $1 \mathrm{~nm}$. The maximum brightness of device $\mathrm{C}$ decreased to $4850 \mathrm{~cd} \mathrm{~m}^{-2}$ because of the limited hole current. However, the LE and EQE of device $\mathrm{C}$ was greatly improved to $5.3 \mathrm{~cd} \mathrm{~A}^{-1}$ and $6.3 \%$, suggesting the increased carrier recombination efficiency in the EL process. The EQE still remains at a high value of $5.1 \%$ at a brightness of $1000 \mathrm{~cd} \mathrm{~m}^{-2}$. The following two reasons should be attributed to the superior device performance. First, the fine-tuned hole injection ability leads to more balanced hole-electron carriers. Second, the recombination zone is well confined in the EML, which can be proved by the disappearance of the TPBI tail emission in the EL spectrum of device C. As a result, the CIE coordinates of the red electroluminescence were also optimized from $(0.63,0.36)$ of device $\mathrm{B}$ to $(0.64,0.35)$ of device $\mathrm{C}$ at a driving voltage of $7.0 \mathrm{~V}$, which is close to those of the standard red device $(0.64,0.33)$ of NTSC (National Television System Committee).

The EQE of a device based on fluorescent materials is the product of charge recombination efficiency $\left(\eta_{1}\right)$, the singlet ratio of the generated exciton $\left(\eta_{2}\right)$, the radiative decay efficiency of the singlet exciton $\left(\eta_{3}\right)$ and the light out-coupling efficiency $\left(\eta_{4}\right)$ of the emission. Usually, the $\eta_{4} \approx 1 /\left(2 n^{2}\right) \approx 20 \%$ for a glass substrate with a refraction index (n) of 1.5. Assuming that $\eta_{1}$ of our device is $100 \%$, the $\eta_{2}$ of the neat RMC2-based device C is calculated to be $77 \%$, considering that the PL efficiency $\left(\eta_{3}\right)$ of the RMC2 neat film is $41 \%$. This is relatively higher than the $25 \%$ singlet exciton generation ratio for conventional fluorescent emitters. According to the previously reported NT derivative-based red OLEDs, ${ }^{47-50}$ the high singlet exciton generation ratio of RMC2 is probably ascribed to the hybrid local and charge-transfer (HLCT) transition mechanism, which provides a reverse intersystem crossing (RISC) process through the intramolecular $T_{2}$ to $S_{2} / S_{1}$ state transition, and induces the terminal singlet exciton ratio to exceed $25 \%$ of spin statistics in OLEDs.

\section{Conclusions}

In summary, through tuning the electron donating ability of 2,1,3-naphthodiazole derivatives, we obtained a saturated red emitter RMC2 with a superior PL efficiency/colour purity tradeoff feature in the PL process and a charge injection/recombination efficiency trade-off feature in the EL process. Optimized red OLEDs based on neat RMC2 realized a maximum LE of $5.3 \mathrm{~cd} \mathrm{~A}^{-1}$, a maximum EQE value of $6.3 \%$ and good CIE coordinates of $(0.64,0.35)$. What's more, the red OLEDs exhibit relatively low efficiency roll-off properties. At a high luminance of up to $1000 \mathrm{~cd} \mathrm{~m}^{-2}$, the maximum EQE value of $81 \%$ is retained. Our results also reveal that it is important to fine tune the balance of hole injection and transporting ability to improve the device performance of non-doped red OLEDs.

\section{Conflicts of interest}

There are no conflicts to declare.

\section{Acknowledgements}

We gratefully acknowledge support of this work by the Hundred Talents Program of Sun Yat-Sen University (76190-18841211) and the National Natural Science and Foundation of China (NSFC, 61905206).

\section{References}

1 C. Y. Chan, M. Tanaka, Y. T. Lee, Y. W. Wong, H. Nakanotani, T. Hatakeyama and C. Adachi, Nat. Photonics, 2021, 15, 203. 
2 T. A. Lin, T. Chatterjee, W. L. Tsai, W. K. Lee, M. J. Wu, M. Jiao, K. C. Pan, C. L. Yi, C. L. Chung, K. T. Wong and C. C. Wu, Adv. Mater., 2016, 28, 6976.

3 H. Lim, H. J. Cheon, S. J. Woo, S. K. Kwon, Y. H. Kim and J. J. Kim, Adv. Mater., 2020, 32, 2004083.

4 Q. Feng, X. Zheng, H. Wang, H. Zhang, Y. Qian, K. Tan, H. Cao, L. Xie and W. Huang, Mater. Adv., 2021, 2, 4000.

5 J. W. Sun, J. H. Lee, C. K. Moon, K. H. Kim, H. Shin and J. J. Kim, Adv. Mater., 2014, 26, 5684.

6 R. Braveenth, H. Lee, S. Kim, K. Raagulan, S. Kim, J. H. Kwon and K. Y. Chai, J. Mater. Chem. C, 2019, 7, 7672.

7 H. Wang, B. Zhao, P. Ma, Z. Li, X. Wang, C. Zhao, X. Fan, L. Tao, C. Duan, J. Zhang, C. Han, G. Chen and H. Xu, J. Mater. Chem. C, 2019, 7, 7525.

8 J. X. Chen, Y. F. Xiao, K. Wang, D. Sun, X. C. Fan, X. Zhang, M. Zhang, Y. Z. Shi, J. Yu, F. X. Geng, C. S. Lee and X. H. Zhang, Angew. Chem., Int. Ed., 2021, 60, 2478.

9 W. Zeng, T. Zhou, W. Ning, C. Zhong, J. He, S. Gong, G. Xie and C. Yang, Adv. Mater., 2019, 31, 1901404.

10 M. Yang, I. S. Park and T. Yasuda, J. Am. Chem. Soc., 2020, 142, 19468.

11 L. Gan, Z. Xu, Z. Wang, B. Li, W. Li, X. Cai, K. Liu, Q. Liang and S. J. Su, Adv. Funct. Mater., 2019, 29, 1808088.

12 X. Gong, P. Li, Y. H. Huang, C. Y. Wang, C. H. Lu, W. K. Lee, C. Zhong, Z. Chen, W. Ning, C. C. Wu, S. Gong and C. Yang, Adv. Funct. Mater., 2020, 30, 1908839.

13 S. Kothavale, K. H. Lee and J. Y. Lee, ACS Appl. Mater. Interfaces, 2019, 11, 17583.

14 J. X. Chen, W. W. Tao, W. C. Chen, Y. F. Xiao, K. Wang, C. Cao, J. Yu, S. Li, F. X. Geng, C. Adachi, C. S. Lee and X. H. Zhang, Angew. Chem., Int. Ed., 2019, 58, 14660.

15 R. Furue, K. Matsuo, Y. Ashikari, H. Ooka, N. Amanokura and T. Yasuda, Adv. Opt. Mater., 2018, 6, 1701147.

16 J. Xue, Q. Liang, R. Wang, J. Hou, W. Li, Q. Peng, Z. Shuai and J. Qiao, Adv. Mater., 2019, 31, 1808242.

17 S. Kothavale, W. J. Chung and J. Y. Lee, J. Mater. Chem. C, 2020, 8, 7059.

18 R. Furue, T. Nishimoto, I. S. Park, J. Lee and T. Yasuda, Angew. Chem., Int. Ed., 2016, 55, 7171.

19 F. M. Xie, P. Wu, S. J. Zou, Y. Q. Li, T. Cheng, M. Xie, J. X. Tang and X. Zhao, Adv. Electron. Mater., 2020, 6, 1900843.

20 F. Ni, Z. Wu, Z. Zhu, T. Chen, K. Wu, C. Zhong, K. An, D. Wei, D. Ma and C. Yang, J. Mater. Chem. C, 2017, 5, 1363.

21 Q. Zhang, H. Kuwabara, W. J. Potscavage, S. Huang, Y. Hatae, T. Shibata and C. Adachi, J. Am. Chem. Soc., 2014, 136, 18070.

22 B. Wang, X. Qiao, Z. Yang, Y. Wang, S. Liu, D. Ma and Q. Wang, Org. Electron., 2018, 59, 32.

23 T. Yang, Z. Cheng, Z. Li, J. Liang, Y. Xu, C. Li and Y. Wang, Adv. Funct. Mater., 2020, 30, 2002681.

24 T. Chen, C. H. Lu, C. W. Huang, X. Zeng, J. Gao, Z. Chen, Y. Xiang, W. Zeng, Z. Huang, S. Gong, C. C. Wu and C. Yang, J. Mater. Chem. C, 2019, 7, 9087.

25 Y. Liu, Y. Chen, H. Li, S. Wang, X. Wu, H. Tong and L. Wang, ACS Appl. Mater. Interfaces, 2020, 12, 30652.
26 J. X. Chen, W. W. Tao, Y. F. Xiao, K. Wang, M. Zhang, X. C. Fan, W. C. Chen, J. Yu, S. Li, F. X. Geng, X. H. Zhang and C. S. Lee, ACS Appl. Mater. Interfaces, 2019, 11, 29086.

27 C. Li, R. Duan, B. Liang, G. Han, S. Wang, K. Ye, Y. Liu, Y. Yi and Y. Wang, Angew. Chem., Int. Ed., 2017, 56, 11525.

28 S. Wang, Z. Cheng, X. Song, X. Yan, K. Ye, Y. Liu, G. Yang and Y. Wang, ACS Appl. Mater. Interfaces, 2017, 9, 9892.

29 P. Chen, L. P. Wang, W. Y. Tan, Q. M. Peng, S. T. Zhang, X. H. Zhu and F. Li, ACS Appl. Mater. Interfaces, 2015, 7, 2972.

30 B. Wang, H. Yang, Y. Zhang, G. Xie, H. Ran, T. Wang, Q. Fu, Y. Ren, N. Sun, G. Zhao, J. Y. Hu and Q. Wang, J. Mater. Chem. C, 2019, 7, 12321.

31 S. Wang, X. Yan, Z. Cheng, H. Zhang, Y. Liu and Y. Wang, Angew. Chem., Int. Ed., 2015, 54, 13068.

32 T. Yang, B. Liang, Z. Cheng, C. Li, G. Lu and Y. Wang, J. Phys. Chem. C, 2019, 123, 18585.

33 Y. L. Zhang, Q. Ran, Q. Wang, Y. Liu, C. Hänisch, S. Reineke, J. Fan and L. S. Liao, Adv. Mater., 2019, 31, 1902368.

34 B. Zhao, H. Wang, C. Han, P. Ma, Z. Li, P. Chang and H. Xu, Angew. Chem., Int. Ed., 2020, 59, 19042.

35 C. Zhou, W. C. Chen, H. Liu, X. Cao, N. Li, Y. Zhang, C. S. Lee and C. Yang, J. Mater. Chem. C, 2020, 8, 9639.

36 W. C. Chen, B. Huang, S. F. Ni, Y. Xiong, A. L. Rogach, Y. Wan, D. Shen, Y. Yuan, J. X. Chen, M. F. Lo, C. Cao, Z. L. Zhu, Y. Wang, P. Wang, L. S. Liao and C. S. Lee, Adv. Funct. Mater., 2019, 29, 1903112.

37 Z. Li, D. Yang, C. Han, B. Zhao, H. Wang, Y. Man, P. Ma, P. Chang, D. Ma and H. Xu, Angew. Chem., Int. Ed., 2021, 60, 14846.

38 H. Yu, X. Song, N. Xie, J. Wang, C. Li and Y. Wang, Adv. Funct. Mater., 2021, 31, 2007511.

39 X. Ai, E. W. Evans, S. Dong, A. J. Gillett, H. Guo, Y. Chen, T. J. H. Hele, R. H. Friend and F. Li, Nature, 2018, 563, 536.

40 Y. Pan, Y. Guo, M. Zhao, C. Li and B. Yang, Mater. Adv., 2021, 2, 1351.

41 Y. Xu, X. Liang, X. Zhou, P. Yuan, J. Zhou, C. Wang, B. Li, D. Hu, X. Qiao, X. Jiang, L. Liu, S. J. Su, D. Ma and Y. Ma, Adv. Mater., 2019, 31, 1807388.

42 C. Fu, S. Luo, Z. Li, X. Ai, Z. Pang, C. Li, K. Chen, L. Zhou, F. Li, Y. Huang and Z. Lu, Chem. Commun., 2019, 55, 6317.

43 T. Liu, X. Chen, J. Zhao, W. Wei, Z. Mao, W. Wu, S. Jiao, Y. Liu, Z. Yang and Z. Chi, Chem. Sci., 2021, 12, 5171.

44 Q. Wan, J. Tong, B. Zhang, Y. Li, Z. Wang and B. Z. Tang, Adv. Opt. Mater., 2020, 8, 1901520.

45 S. Wang, H. Zhang, B. Zhang, Z. Xie and W. Y. Wong, Mater. Sci. Eng., R, 2020, 140, 100547.

46 X. Chen, Z. Yang, W. Li, Z. Mao, J. Zhao, Y. Zhang, Y. C. Wu, S. Jiao, Y. Liu and Z. Chi, ACS Appl. Mater. Interfaces, 2019, 11, 39026.

47 T. Liu, L. Zhu, C. Zhong, G. Xie, S. Gong, J. Fang, D. Ma and C. Yang, Adv. Funct. Mater., 2017, 27, 1606384.

48 W. Li, Y. Pan, L. Yao, H. Liu, S. Zhang, C. Wang, F. Shen, P. Lu, B. Yang and Y. Ma, Adv. Opt. Mater., 2014, 2, 892. 
49 W. Li, Y. Pan, R. Xiao, Q. Peng, S. Zhang, D. Ma, F. Li, F. Shen, Y. Wang, B. Yang and Y. Ma, Adv. Funct. Mater., 2014, 24, 1609.

50 T. Liu, L. Zhu, S. Gong, C. Zhong, G. Xie, E. Mao, J. Fang, D. Ma and C. Yang, Adv. Opt. Mater., 2017, 5, 1700145.

51 L. Chen, L. Wang, X. Jing and F. Wang, J. Mater. Chem., 2011, 21, 10265.

52 L. Chen, H. Tong, Z. Xie, L. Wang, X. Jing and F. Wang, J. Mater. Chem., 2011, 21, 15773.

53 L. Chen, B. Zhang, Y. Cheng, Z. Xie, L. Wang, X. Jing and F. Wang, Adv. Funct. Mater., 2010, 20, 3143.

54 L. Chen, P. Li, Y. Cheng, Z. Xie, L. Wang, X. Jing and F. Wang, Adv. Mater., 2011, 23, 2986.

55 L. Chen, P. Li, H. Tong, Z. Xie, L. Wang, X. Jing and F. Wang, J. Polym. Sci., Part A: Polym. Chem., 2012, 50, 2854.
56 P. J. Homnick and P. M. Lahti, Phys. Chem. Chem. Phys., 2012, 14, 11961.

57 H. You, Y. Dai, Z. Zhang and D. Ma, J. Appl. Phys., 2007, 101, 026105.

58 K. Kanai, K. Koizumi, S. Ouchi, Y. Tsukamoto, K. Sakanoue, Y. Ouchi and K. Seki, Org. Electron., 2010, 11, 188.

59 Z. Ning, Z. Chen, Q. Zhang, Y. Yan, S. Qian, Y. Cao and H. Tian, Adv. Funct. Mater., 2007, 17, 3799.

60 C. Chen, Y. Wei, J. Lin, M. V. R. K. Moturu, W. Chao, Y. Tao and C. Chien, J. Am. Chem. Soc., 2006, 128, 10992.

61 B. W. Wu, H. Yeh, L. Chan and C. Chen, Adv. Mater., 2002, 14, 1072.

62 J. Yu, N. Wang, Y. Zang and Y. Jiang, Sol. Energy Mater. Sol. Cells, 2011, 95, 664.

63 J. Huang, X. Qiao, Y. Xia, X. Zhu, D. Ma, Y. Cao and J. Roncali, Adv. Mater., 2008, 20, 4172. 